\title{
Analysis of the Dynamic Behaviour of Steel-Concrete Composite Footbridges Considering the Soil-Structure Interaction
}

\author{
J.G. Santos da Silva*, A.C.C. Fontenla Sieira*, G.L. Debona** \\ *(Structural Engineering Department. State University of Rio de Janeiro. Rio de Janeiro/RJ, Brazil) \\ **(Civil Engineering Post-graduate Programme. State University of Rio de Janeiro, Rio de Janeiro/RJ, Brazil)
}

\begin{abstract}
The main objective of this investigation is to present the finite element modelling of the dynamic behaviour of a steel-concrete composite footbridge, when subjected to human walking vibrations. The investigated structural system was based on a tubular steel-concrete composite footbridge, spanning $82.5 \mathrm{~m}$. The structural model consists of tubular steel sections and a concrete slab. This investigation is carried out based on correlations between the experimental results related to the footbridge dynamic response and those obtained with finite element modelling. The soil-structure interaction effect was considered in the dynamic analysis based on the use of Winkler's theory. The finite element model enabled a complete dynamic evaluation of the tubular footbridge in terms of human comfort and its associated vibration serviceability limit states. The peak accelerations found in this analysis indicated that the investigated footbridge presented problems related with human comfort and it was detected that the structural system can reach vibration levels that compromise the footbridge user's comfort.
\end{abstract}

Keywords - Footbridges, Structural dynamics, Soil-structure interaction, Numerical modelling, Human comfort.

\section{INTRODUCTION}

Steel and steel-concrete pedestrian footbridges are more and more becoming the modern landmarks of urban areas. Designers seem to continuously move the safety border, in order to increase slenderness and lightness of their footbridges [1-3]. However, more and more pedestrian footbridges are carried out as light weight structures with low natural frequencies and low structural damping [1-8]. On the other hand, the structural engineers experience and knowledge allied by the use newly developed materials and technologies have produced pedestrian footbridges with daring structures [1-8].These facts have generated very slender pedestrian footbridges, sensitive to dynamic excitation, and consequently changed the serviceability and ultimate limit states associated to their design. A direct consequence of this design trend is a considerable increase of structural excessive vibrations problems [1-5].

Hence, the frequency of the actions associated to pedestrians (walking or running) may coincide with the fundamental frequency of the structure (resonance) and dynamic effects can't be neglected. It is also known that the dynamic response of the footbridges in resonance with the human-induced dynamic loads is considerably amplified when compared to the static response. Thus, these structures may vibrate excessively and cause discomfort to the pedestrians. Therefore, structural engineers must avoid designing footbridges resonance with the human-induced dynamic loads.Considering all aspects mentioned before, the main objective of this investigation is to present the finite element modelling of the dynamic behaviour of steel-concrete composite footbridges submitted to human walking vibration. The investigated structural model was based on a tubular steel-concrete composite footbridge, spanning 82.5 $\mathrm{m}$. The structure is composed by three spans $(32.5$ $\mathrm{m}, 17.5 \mathrm{~m}$ and $20.0 \mathrm{~m}$, respectively) and two overhangs $(7.50 \mathrm{~m}$ and $5.0 \mathrm{~m}$, respectively). The structural system consists of tubular steel sections and a concrete slab and is currently used for pedestrian crossing $[1,2]$.

The proposed computational model adopted the usual mesh refinement techniques present in finite element method simulations, based on the ANSYS program [9]. The finite element model has been developed and validated with the experimental results. It must be emphasized that the soil-structure interaction effect was considered in the finite element modelling of the investigated pedestrian footbridge. This numerical model enabled a complete dynamic evaluation of the investigated tubular footbridge especially in terms of human comfort and its associated vibration serviceability limit states [1-3].This investigation is carried out based on correlations between the experimental results related to the footbridge dynamic response and those obtained with finite element models. The proposed computational model adopted the usual mesh refinement techniques present in finite element method simulations [1-3].The structural system dynamic response, in terms of peak accelerations, was obtained and compared to the limiting values 
proposed by several authors and design standards [6, 7]. The peak acceleration values found in the present investigation indicated that the analysed tubular footbridge presented problems related with human

\section{HUMAN WALKING MODELLING}

The present investigation was carried out based on a loading model developed to incorporate the dynamic effects induced by people walking [10]. The loading model considered the ascent and descending movement of the human body effective mass at each step and the position of the dynamic comfort. Hence it was detected that this type of structure can reach high vibration levels that can compromise the footbridge user's comfort and especially its safety.

load (human walking load) was also changed according to the individual position.This dynamic loading model considers a space and time variation of the dynamic action over the structure that is evaluated. Additionally, also incorporates the transient effect due to the human heel impact, see Equations (1) to (4) [10]:

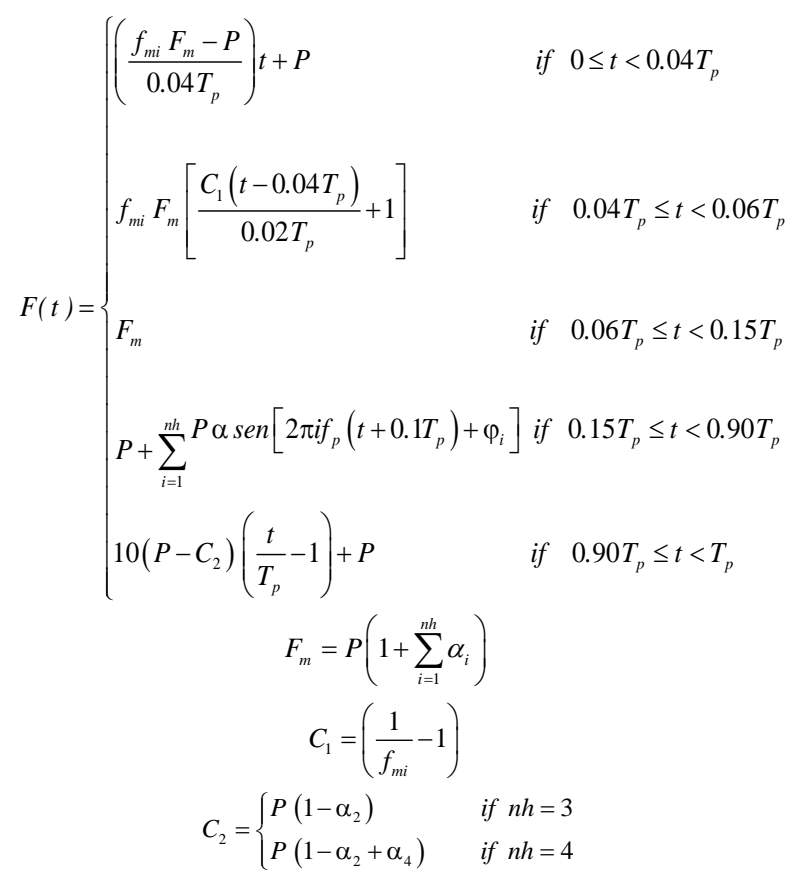

Where:

$\mathrm{F}_{\mathrm{m}}$ : maximum Fourier series value (2);

$\mathrm{f}_{\mathrm{mi}}$ : human heel impact factor;

$\mathrm{T}_{\mathrm{p}}$ : step period;

$\mathrm{f}_{\mathrm{s}}$ : step frequency;

$\Phi$ : harmonic phase angle;

P: person's weight;

$\alpha_{\mathrm{i}}$ : dynamic coefficient for the harmonic force;

i: harmonic multiple $(i=1,2,3 \ldots, n)$;

$\mathrm{t}$ : time;

$\mathrm{C}_{1}$ and $\mathrm{C} 2$ : coefficients given by (3-4).

The proposed mathematical model used to represent the dynamical actions produced by people walking on the floor slabs is not simply a Fourier series, due to the fact that the mentioned equations also incorporate the human heel impact effect [10]. The present investigation used a heel impact factor equal to $1.12\left(f_{m i}=1.12\right)$. However, it must be emphasized that this value can vary substantially from person-to-person [1, 10]. The pedestrian motion on the footbridge was modelled based on the Equations (1) to (4) and four harmonics were used to

generate the dynamic forces produced by human walking. Figure 1 illustrates the dynamic load function for an individual walking at a step frequency of $2.0 \mathrm{~Hz}\left(\mathrm{f}_{\mathrm{s}}=2.0 \mathrm{~Hz}\right)$. Considering the investigated footbridge, the third harmonic with step frequency equal to $2.0 \mathrm{~Hz} \quad\left(\mathrm{f}_{\mathrm{s}}=2.0 \mathrm{~Hz}\right)$ was considered the resonant harmonic of the walking load $(3 \times 2.0 \mathrm{~Hz}=6.0 \mathrm{~Hz})$. In this situation, the finite element mesh has to be very refined and the contact time of application of the dynamic load over the structure depends of the step distance and step frequency, see Table 1.The following strategy was adopted in this study: a step distance equal to $0.75 \mathrm{~m}$ corresponding to the third harmonic with step frequency of $2.0 \mathrm{~Hz}$ was used, see Table 1 . The step period is equal to $1 / \mathrm{f}_{\mathrm{s}}=1 / 2.0 \mathrm{~Hz}=0.50 \mathrm{~s}$, corresponding to a distance of $0.75 \mathrm{~m}$. This way, the adopted strategy considered three forces to model one human step and each of the dynamic loads P1, P2 and P3 were applied to the footbridge structure during $0.50 / 3=0.1667 \mathrm{~s}$, corresponding to the contact time of each load. 


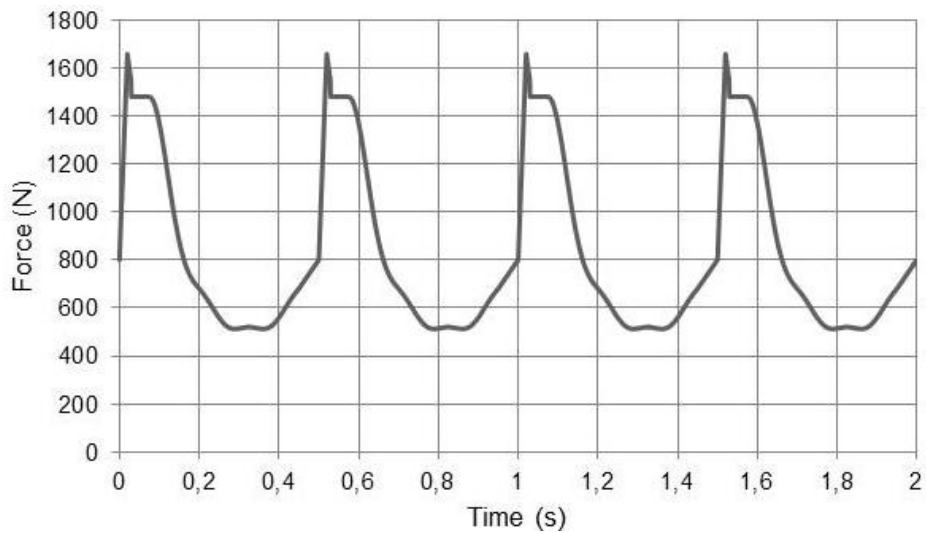

Figure 1. Dynamic load function for one person walking $\left(\mathrm{f}_{\mathrm{s}}=2.0 \mathrm{~Hz}\right)$. Resonant harmonic of the walking load $\left(3^{\text {rd }}\right.$ harmonic: $3 \times 2.0 \mathrm{~Hz}=6.0 \mathrm{~Hz}$ ).

Table 1. Step frequencies $\left(f_{s}\right)$, dynamic coefficients $\left(\alpha_{i}\right)$ and phase angles $\left(\phi_{i}\right)[6,7]$.

\begin{tabular}{|l|l|l|l|}
\hline Harmonic i & $\mathrm{f}_{\mathrm{s}}(\mathrm{Hz})$ & $\alpha_{\mathrm{i}}$ & $\phi_{\mathrm{i}}$ \\
\hline 1 & $1.6-2.2$ & 0.50 & 0 \\
\hline 2 & $3.2-4.4$ & 0.20 & $\pi / 2$ \\
\hline 3 & $4.8-6.6$ & 0.10 & $\pi$ \\
\hline 4 & $6.4-8.8$ & 0.05 & $3 \pi / 2$ \\
\hline
\end{tabular}

However, the dynamic forces were not simultaneously applied. The load application begins with the first human step where the first load, P1 is applied for $0.1667 \mathrm{~s}$, see Equations 1 to 4 . At the end of this time period, the load P1 becomes zero while the load P2 is subsequently applied for $0.1667 \mathrm{~s}$. The process continues with the application of the other load P3, based on the same procedure previously described, until the end of the first step. At this point, the load $\mathrm{P} 3$ from the first step is made equal to the load P1 of the second step. The process continues with subsequent step applications until all dynamic loads are applied along the entire structure length. It can be concluded that all the dynamic actions associated will be applied over the structure.

\section{SOIL-STRUCTURE INTERACTION}

The soil data were obtained using three boreholes (standard penetration tests: SPT) at a depth varying from $2.67 \mathrm{~m}$ to $22.70 \mathrm{~m}$. The boreholes gave the geotechnical profile definition that was adopted in the finite element model $[1,2]$. The characterization and resistance tests that were performed in the laboratory provided the specific weight, friction angle and cohesion values are presented in reference [1]. When the study of halfburied columns is considered, the usual methodology for the formulation of the soil-structure interaction problem utilizes the reaction coefficient concept, originally proposed by [11]. In the case of laterally loaded piles, the analysis procedure based on Winkler [11] is analogous to that used for shallow foundations. The soil behaviour is simulated by a group of independent springs governed by a linear-elastic model. The foundation applies a reaction in the column normal direction that is proportional to the column deflection. The spring stiffness, designated as the reaction coefficient $\left(\mathrm{k}_{\mathrm{h}}\right)$, is defined as the pressure necessary to produce a unitary displacement [11], see Equation (5).

$$
k_{h}=\frac{p}{y}
$$

Where:

$$
\begin{aligned}
& \mathrm{p} \text { : applied pressure in }\left(\mathrm{N} / \mathrm{m}^{2}\right) \text {; } \\
& \mathrm{y} \text { : soil deflection in }(\mathrm{m}) .
\end{aligned}
$$

Terzaghi [12] considered that the reaction coefficient $\left(\mathrm{k}_{\mathrm{h}}\right)$ for piles in cohesive soils (clays) does not depend on the depth of the pile and may be determined using the following equation.

$$
k_{h}=\left(\frac{0,3048 m}{1,5 d}\right) k_{s 1}
$$

Where:

$\mathrm{k}_{\mathrm{s} 1}$ : modulus of a squared plate with length equal to $0.3048 \mathrm{~m}$ in $\left(\mathrm{MN} / \mathrm{m}^{3}\right)$;

d: column width (pile) in (m).

In sequence, Table 2 presents typical values for $\mathrm{k}_{\mathrm{s} 1}$ for consolidated clays. For piles in non-cohesive soils (sand), it is assumed that the horizontal reaction coefficient $\left(\mathrm{k}_{\mathrm{h}}\right)$ varies along the depth according to Equation (7).

$$
k_{h}=n_{h} \frac{z}{d}
$$


Table 2. Typical values of $\mathrm{k}_{\mathrm{s1}}$ [12].

\begin{tabular}{|l|l|l|}
\hline Clay's consistency & $\mathrm{k}_{\mathrm{s} 1}\left(\mathrm{t} / \mathrm{ft}^{3}\right)$ & $\mathrm{k}_{\mathrm{s} 1}\left(\mathrm{MN} / \mathrm{m}^{3}\right)$ \\
\hline Stiff & 75 & 26.0 \\
\hline Very stiff & 150 & 52.0 \\
\hline Hard & 300 & 104.0 \\
\hline
\end{tabular}

Where:

$\mathrm{n}_{\mathrm{h}}$ : stiffness for non-cohesive soils, in $\left(\mathrm{MN} / \mathrm{m}^{3}\right)$;

$\mathrm{d}$ : column width (pile), in (m).
Table 3 presents typical values of the stiffness parameter for non-cohesive soils obtained by [12] as a function of the sand relative density under submerged and dry conditions.

Table 3. Typical values of $n_{h}$ [12].

\begin{tabular}{|l|l|l|}
\hline Relative density & $\mathrm{n}_{\mathrm{h}}($ dry $)\left(\mathrm{MN} / \mathrm{m}^{3}\right)$ & $\mathrm{n}_{\mathrm{h}}($ submerged $)\left(\mathrm{MN} / \mathrm{m}^{3}\right)$ \\
\hline Loose & 2.4 & 1.4 \\
\hline Medium & 7.3 & 4.9 \\
\hline Dense & 19.4 & 11.8 \\
\hline
\end{tabular}

Based on the horizontal reaction coefficients values $\left(\mathrm{k}_{\mathrm{h}}\right)$ and the column width, the foundation stiffness parameter $\left(\mathrm{k}_{\mathrm{o}}\right)$ is determined by Equation (8) [13].

$$
k_{0}=k_{h} d
$$

Considering the subsoil geotechnical profile (Figure 2), and using the proposed analysis methodology, based on the Winkler model [11], the horizontal reaction coefficients on the piles $\left(\mathrm{k}_{\mathrm{h}}\right)$ were determined as a function of the soil behaviour. Applying the horizontal reaction coefficients $\left(\mathrm{k}_{\mathrm{h}}\right)$ on Equation (8), the foundation stiffness parameters values $\left(\mathrm{k}_{0}\right)$ were calculated. The foundation stiffness parameters values $\left(\mathrm{k}_{0}\right)$ were used to determine the spring's stiffness $(\mathrm{k})$ that was included in the numerical model to simulate the soil (Figure 2). The spring elements that simulate the piles were discretized based on a range with length of $1 \mathrm{~m}$. This way, a translational spring was placed in the transversal direction of the pile section axis, with a stiffness value obtained for the horizontal reaction coefficient. The spring's stiffness coefficients are presented in reference [1].

\section{INVESTIGATED STRUCTURAL MODEL}

The structural model consists of tubular steel sections and a $100 \mathrm{~mm}$ concrete slab and is currently submitted to human walking loads $[1,2]$. The structure was based on a tubular composite (steel-concrete) footbridge, spanning $82.5 \mathrm{~m}$. The structure is com-posed by three spans $(32.5 \mathrm{~m}, 17.5$ $\mathrm{m}$ and $20.0 \mathrm{~m}$, respectively) and two overhangs (7.50 $\mathrm{m}$ and $5.0 \mathrm{~m}$, respectively), see Figure 3.The steel sections used were welded wide flanges (WWF) made with a $300 \mathrm{MPa}$ yield stress steel grade. A $2.05 \times 10^{5} \mathrm{MPa}$ Young's modulus was adopted for the tubular footbridge steel beams and columns. The concrete slab has a $20 \mathrm{MPa}$ specified compression strength and a $2.13 \times 10^{4} \mathrm{MPa}$ Young's Modulus [1, 2].

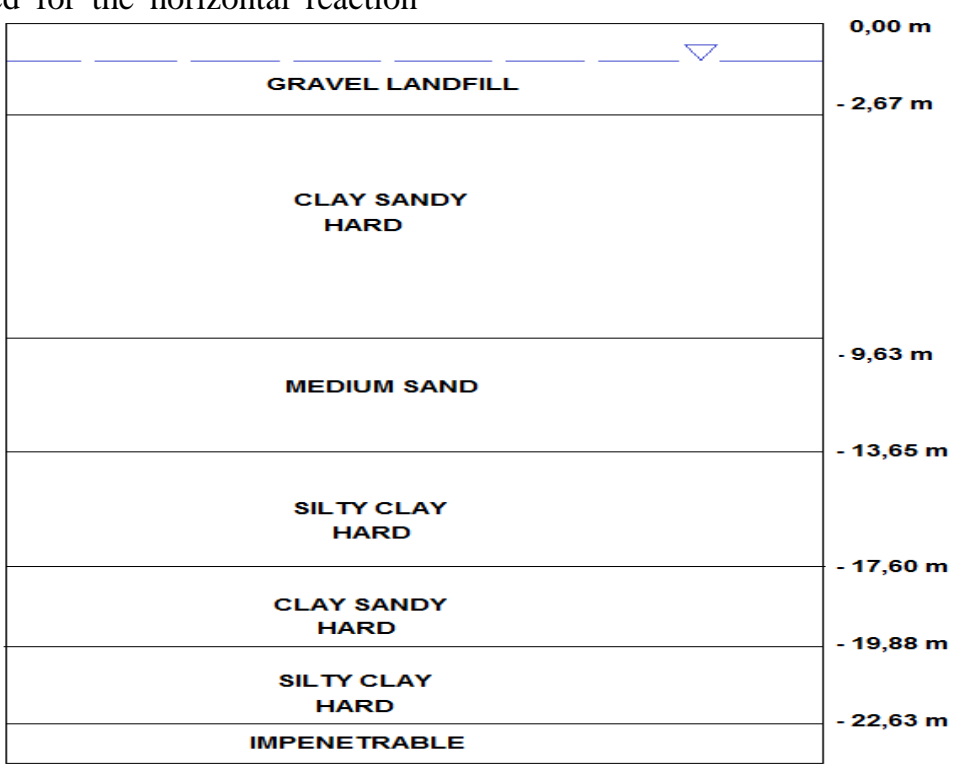

Figure 2. Subsoil geotechnical profile. 


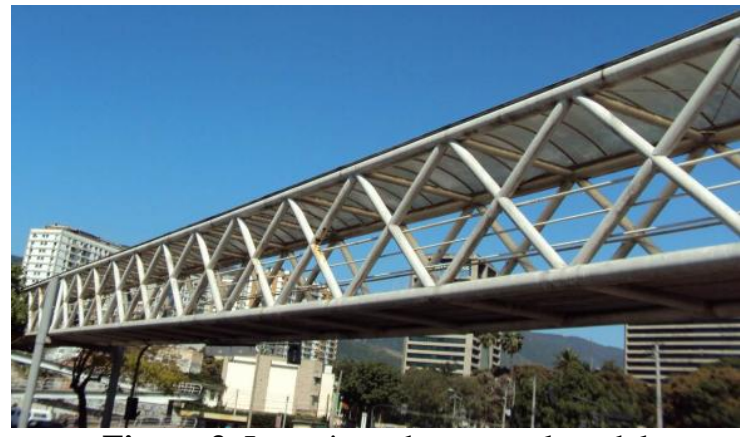

Figure 3. Investigated structural model

\section{FINITE ELEMENT MODEL}

The finite element model adopted the usual mesh refinement techniques present in finite element method simulations, based on the ANSYS program [9]. This numerical model has been developed and validated with the experimental results and enabled a complete dynamic evaluation of the investigated tubular footbridge especially in terms of human comfort and its associated vibration serviceability limit states, see Figure 4. In this model, all steel tubular sections were represented by threedimensional beam elements (PIPE16 and BEAM44) with tension, compression, torsion and bending capabilities. These elements have six degrees of freedom at each node: translations in the nodal $\mathrm{x}, \mathrm{y}$, and $\mathrm{z}$ directions and rotations about $\mathrm{x}, \mathrm{y}$, and $\mathrm{z}$ axes, see Figure 4.

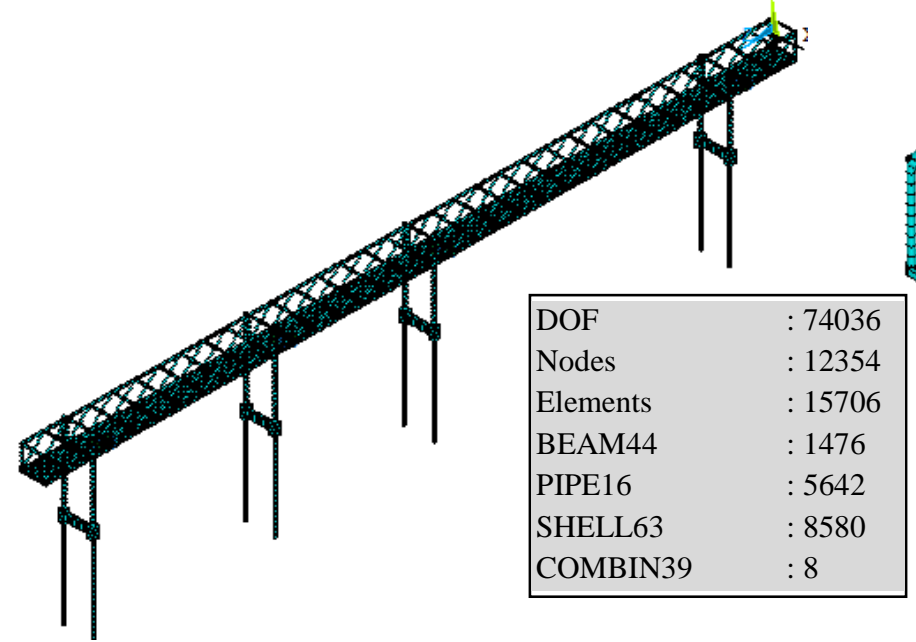

(a) Global trheedimensional view of the structure.

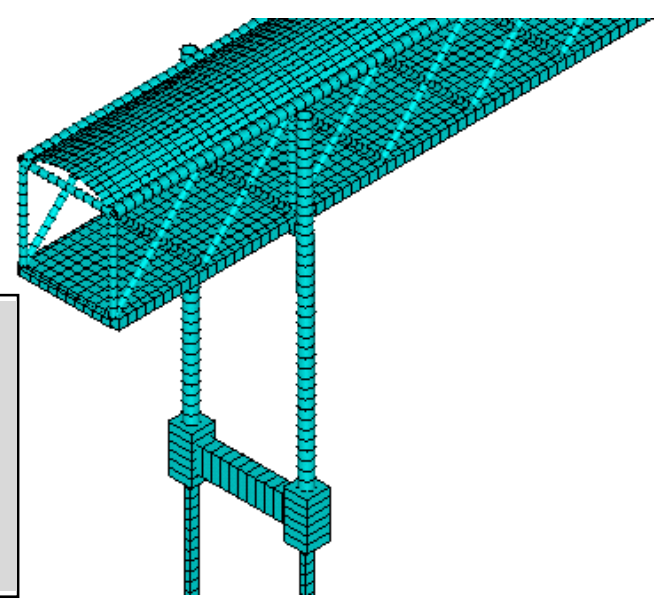

(b) Overhang and span details.

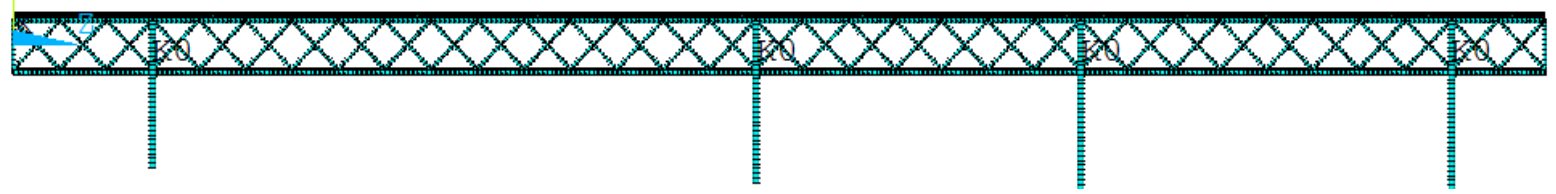

(c) Lateral view of the investigated footbridge.

Figure 4. Steel-concrete composite tubular footbridge finite element model.

The reinforced concrete slab was represented by shell finite elements (SHELL63). This finite element has both bending and membrane capabilities. Both in-plane and normal loads are permitted. The element has six degrees of freedom at each node: translations in the nodal $\mathrm{x}, \mathrm{y}$, and $\mathrm{z}$ directions and rotations about the nodal $\mathrm{x}, \mathrm{y}$, and $\mathrm{z}$ axes.The footbridge pier bearings were represented by a rotational spring element (COMBIN39). This element is a unidirectional element with nonlinear generalized force-deflection capability that can be used in any analysis.The finite element model presented 74036 degrees of freedom, 12354 nodes and 15706 finite elements (BEAM44: 1476; PIPE16: 5642; SHELL63: 8580 and COMBIN39: 8), see Figure 4. It was considered that both structural elements (steel tubular sections and concrete slab) have total interaction with an elastic behaviour. 


\section{DYNAMIC STRUCTURAL}

ANALYSIS

Initially, the composite footbridge natural frequencies, vibration modes and peak accelerations were determined based on experimental tests [2]. The peak acceleration values were obtained considering three types of human walking: slow walking, regular walking and fast walking [1].In a second phase, the steel-concrete composite footbridge natural frequencies vibration modes and peak accelerations were determined with the aid of the numerical simulations, based on the finite element method using the ANSYS program [9].It can be clearly noticed that there is a very good agreement between the structural model natural frequency values calculated using finite element simulations and the experimental results, see Table 4. Such fact validates the finite element model here presented, as well as the results and conclusions obtained throughout this study. The vibration modes of the footbridge are depicted in Figure 5 to 7.

Table 4. Tubular footbridge natural frequencies.

\begin{tabular}{|l|l|l|l|}
\hline Natural frequencies $(\mathrm{Hz})$ & $\mathrm{f}_{01}$ & $\mathrm{f}_{02}$ & $\mathrm{f}_{03}$ \\
\hline Finite element modelling & 1.61 & 2.12 & 5.39 \\
\hline Experimental results & 1.56 & 2.34 & 5.08 \\
\hline Error $(\%)$ & 3.20 & 9.40 & 6.10 \\
\hline
\end{tabular}

When the investigated steel-concrete composite footbridge freely vibrates in a particular mode, it moves up and down with a certain configuration or mode shape. Each footbridge natural frequency has an associated mode shape, see Figures 5 to 7 . Considering the analysed footbridge mode shapes, see Figures 5 to 7 , it was clearly verified that longitudinal amplitudes were predominant in the fundamental vibration mode $\left(\mathrm{f}_{01}\right.$ $=1.61 \mathrm{~Hz}$ ), see Figure 5. In the second mode shape lateral displacements were predominant $\left(\mathrm{f}_{02}=2.12\right.$ $\mathrm{Hz}$ ), as presented in Figure 6. On the other hand, in the third vibration mode $\left(\mathrm{f}_{03}=5.39 \mathrm{~Hz}\right)$, the flexural effects were predominant, as illustrated in Figure 7.

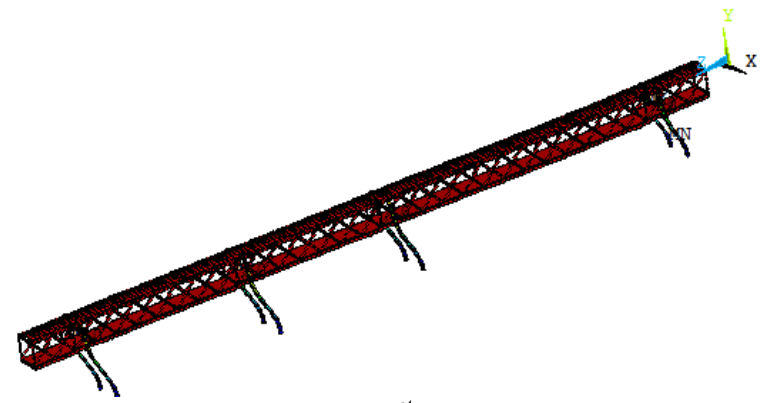

Figure 5. Vibration mode associated with the $1^{\text {st }}$ footbridge natural frequency $\left(\mathrm{f}_{01}=1.61 \mathrm{~Hz}\right)$.

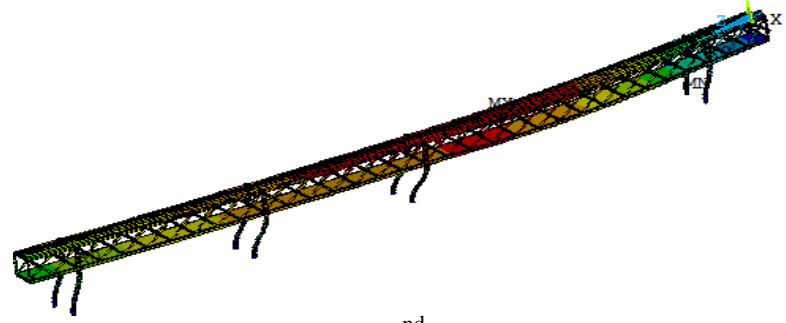

Figure 6. Vibration mode associated with the $2^{\text {nd }}$ footbridge natural frequency $\left(f_{02}=2.12 \mathrm{~Hz}\right)$.

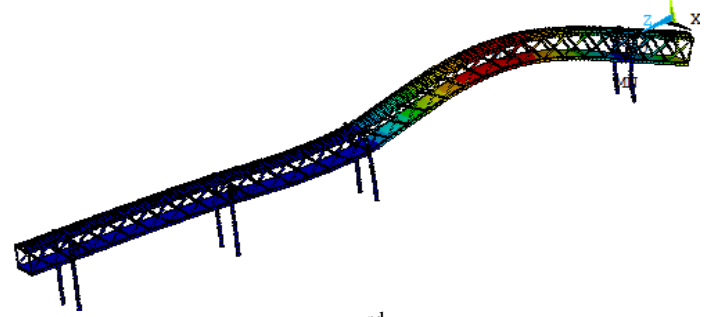

Figure 7. Vibration mode associated with the $3^{\text {rd }}$ footbridge natural frequency $\left(f_{03}=5.39 \mathrm{~Hz}\right)$. 
The finite element modelling follows with the evaluation of the footbridge performance in terms of vibration serviceability due to dynamic forces induced by people walking. The first step of this investigation concerned in the determination of the tubular footbridge peak accelerations, based on a linear time-domain dynamic analysis.The dynamic loading related to one person crossing the tubular footbridge on the concrete slab centre, as presented in Figure 1, was applied over $55.0 \mathrm{~s}$ and an integration time step of $2 \times 10^{-3} \mathrm{~s}\left(\square \mathrm{t}=2 \times 10^{3} \mathrm{~s}\right)$ was adopted in this investigation. The peak accelerations were obtained at seven sections of the analysed structural model, as presented in Figure 8. These maximum accelerations were compared to the limits recommended by design codes [6, 14].

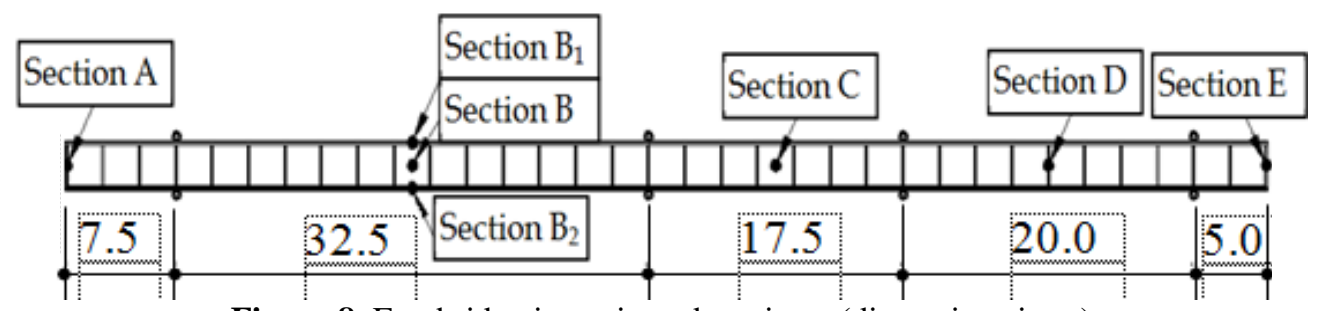

Figure 8. Footbridge investigated sections. (dimensions in $\mathrm{m}$ ).

In sequence, Figure 9 illustrates the tubular footbridge dynamic response, along the time, related to the central section B (see Figure 8), when one pedestrian crosses the footbridge in regular walking (resonance condition $\left[\mathrm{f}_{\mathrm{s}}=2.0 \mathrm{~Hz}\right]$ ).

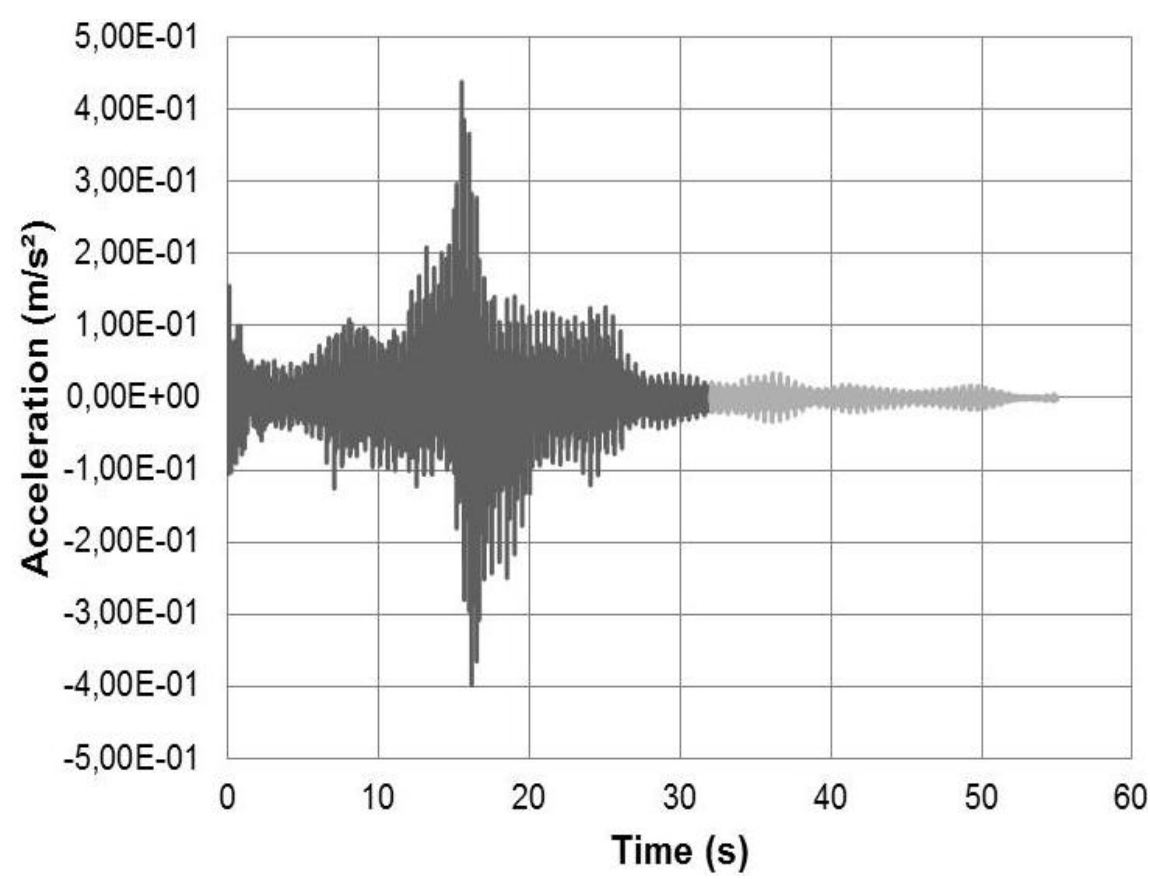

Figure 9. Tubular footbridge acceleration response at central section B. One pedestrian crossing the concrete slab centre at resonance. Regular walking.

Figure 9 presented the vertical acceleration versus time for the tubular footbridge at central section B. This figure shows that the vertical acceleration gradually increase with time. In this particular case, the third harmonic with a $2.0 \mathrm{~Hz}$ step frequency $\left(f_{\mathrm{s}}=2.0 \mathrm{~Hz}\right)$, was the walking load resonant harmonic. The maximum acceleration value found at section B (see Figure 9) was equal to 0.45 $\mathrm{m} / \mathrm{s}^{2}$. Figure 9 also indicates that from the moment that the pedestrian leaves the footbridge span (Section B, see Figure 8), when the time is approximately equal to $26 \mathrm{~s}$, the structural damping minimises the structural model dynamic response, as presented in Figure 9. This assertive occurs in dynamic loading models that consider the load spatial variation. The peak acceleration analysis was focused in three types of human walking: slow walking, regular walking and fast walking. Tables 5 and 6 present the maximum accelerations (peak accelerations: $a_{p}$ in $\mathrm{m} / \mathrm{s}^{2}$ ), related to seven sections of the investigated footbridge (A, B, B1, B2, C, D and E), see Figure 8. 
Table 5. Peak accelerations corresponding to individual walking: Sections A, B1, B and B2.

\begin{tabular}{|c|c|c|c|c|}
\hline \multicolumn{5}{|c|}{ Footbridge peak accelerations $\left(a_{p}\right.$ in $\left.\mathrm{m} / \mathrm{s}^{2}\right)$} \\
\hline \multicolumn{5}{|c|}{ S: slow walking } \\
\hline \multicolumn{5}{|c|}{ R: regular walking } \\
\hline \multicolumn{5}{|c|}{ F: fast walking } \\
\hline Walking & A & B1 & $\mathrm{B}$ & B2 \\
\hline $\mathrm{S}$ & 1.15 & 0.22 & \begin{tabular}{|l|l|}
0.57 &
\end{tabular} & 0.22 \\
\hline $\mathrm{R}$ & 1.00 & 0.16 & 0.45 & 0.16 \\
\hline $\mathrm{F}$ & 1.41 & 0.18 & 0.62 & 0.18 \\
\hline
\end{tabular}

Table 6. Peak accelerations corresponding to individual walking: Sections C, D and E.

\begin{tabular}{|c|c|c|c|}
\hline Footbridg & in $n$ & & \\
\hline S: slow w & & & \\
\hline R: regular & & & \\
\hline$\overline{\mathrm{F}: \text { fast wa }}$ & & & \\
\hline Walking & $\mathrm{C}$ & $\mathrm{D}$ & $E$ \\
\hline S & 0.67 & 0.54 & 0.94 \\
\hline$\overline{\mathrm{R}}$ & 0.38 & 0.33 & 0.78 \\
\hline $\bar{F}$ & 0.75 & 0.55 & 1.58 \\
\hline $\mathrm{a}_{\text {lim }}=1.5$ & footh & & \\
\hline $\mathrm{a}_{\lim }=5.0^{c}$ & or foo & & \\
\hline
\end{tabular}

The maximum acceleration values (peak accelerations) are respectively equal to $1.41 \mathrm{~m} / \mathrm{s}^{2}$ (Section A), $0.62 \mathrm{~m} / \mathrm{s}^{2}$ (Section B), $0.75 \mathrm{~m} / \mathrm{s}^{2}$ (Section C), $0.54 \mathrm{~m} / \mathrm{s}^{2}$ (Section D) and $1.58 \mathrm{~m} / \mathrm{s}^{2}$ (Section E), see Tables 5 and 6. These peak accelerations presented in Tables 5 and 6 are related to a pedestrian fast walking situation. It must be emphasized that the limit acceleration value is equal to $0.49 \mathrm{~m} / \mathrm{s}^{2}$, when outdoor footbridges are considered in the analysis $[6,14]$.Based on the finite element modelling of the steel-concrete composite footbridge dynamic behaviour, the numerical results presented in Tables 5 and 6 indicated that the dynamic actions produced by human walking led to peak accelerations higher than the limiting values present in design code recommendations (Outdoor footbridges: $\left.5 \% \mathrm{~g}=0.49 \mathrm{~m} / \mathrm{s}^{2}\right),[6,14]$, as depicted in Tables 5 and 6 .

\section{CONCLUSIONS}

This contribution covers the application of tubular structural elements in pedestrian footbridge design and tries to give an overview about the evaluation of tubular footbridges dynamic behaviour, objectifying to help practical structural engineers to deal with this kind of problem and to allow for a further application of tubular structural elements in pedestrian footbridge design.The present study was carried out based on a realistic loading model developed to incorporate the dynamic effects induced by people walking. The loading model considered the ascent and descending movement of the human body effective mass at each step and the position of the dynamic load (human walking load) was also changed according to the individual position. Additionally, also incorporates the transient effect due to the human heel impact.The proposed analysis methodology considered the investigation of the dynamic behaviour, in terms of serviceability limit states, of a tubular composite (steel-concrete) footbridge, spanning $82.5 \mathrm{~m}$. The structure is composed by three spans $(32.5 \mathrm{~m}, 17.5 \mathrm{~m}$ and 20.0 $\mathrm{m}$, respectively) and two overhangs (7.50 $\mathrm{m}$ and 5.0 $\mathrm{m}$, respectively). The structural system consists of tubular steel sections and a concrete slab and is currently used for pedestrian crossing.A computational model, based on the finite element method, was developed using the ANSYS program. This model enabled a complete dynamic evaluation of the investigated pedestrian footbridge, including in the analysis the soil-structure interaction effect, especially in terms of human comfort and its associated vibration serviceability limit states. The results found throughout this investigation have indicated that the dynamic actions produced by human walking could generate peak accelerations that surpass design criteria limits developed for ensuring human comfort. Hence it was detected that this type of structure can reach high vibration levels that can compromise the footbridge user's comfort. 


\section{ACKNOWLEDGEMENTS}

The authors gratefully acknowledge the financial support for this work provided by the Brazilian Science Foundation's CAPES, CNPq and FAPERJ.

\section{REFERENCES}

[1]. Debona, G.L. Modelagem do comportamento dinâmico de passarelas tubulares em aço e mistas (aço-concreto) (Modelling of the dynamic behaviour of composite (steel-concrete) tubular footbridges), MSc Dissertation (in Portuguese), Civil Engineering PostGraduate Programme, PGECIV, State University of Rio de Janeiro, UERJ, Rio de Janeiro, Brazil, pp. 1-152, 2011.

[2]. Zúñiga, J. E. V. Análise da resposta dinâmica experimental de uma passarela tubular mista, aço-concreto, submetida ao caminhar humano (Dynamic experimental analysis of a composite (steel-concrete) tubular footbridge submitted to human walking), MSc Dissertation (in Portuguese), Civil Engineering Post-Graduate Programme, PGECIV, State University of Rio de Janeiro, UERJ, Rio de Janeiro, Brazil, pp. 1-135, 2011.

[3]. Figueiredo, F.P., Silva, J.G.S. da, Vellasco, P.C.G. da S., Lima, L.R.O. de, Andrade, S.A.L. de. A parametric study of composite footbridges under pedestrian walking loads. Engineering Structures, 30: 605-615, 2008.

[4]. Pimentel, R.L., Pavic, A., Waldron, P. Evaluation of design requirements for footbridges excited by vertical forces from walking. Canadian Journal of Civil Engineering, Vol. 28(5), 769-776, 2001.

[5]. Silva, J.G.S. da, Vellasco, P.C.G. da S., Andrade, S.A.L. de, Lima, L.R.O. de, Figueiredo, F.P. Vibration analysis of footbridges due to vertical human loads. Computers \& Structures, 85: 1693-1703, 2007.
[6]. Murray, T.M., Allen, D.E., Ungar, E.E. Floor vibrations due to human activity, Steel Design Guide Series, American Institute of Steel Construction, AISC, Chicago, USA, 2003.

[7]. Bachmann, H., Ammann W.J., Deischl, F., Eisenmann, J., Floegl J., Hirsch, G.H., et al., "Vibration problems in structures practical guidelines", Basel (Switzerland):Institut für Baustatik und Konstruktion, Birkhäuser; 1995.

[8]. Chen, Y. Finite element analysis for walking vibration problems for composite precast building floors using ADINA: modelling, simulation and comparison. Computer \& Structures, 72:109-126, 1999.

[9]. ANSYS. Swanson Analysis Systems, Inc. P.O. Box 65, Johnson Road, Houston, PA, 15342-0065, Version 10.0, Basic analysis procedures, Second edition, 2003.

[10]. Varela, W.D. Modelo teórico-experimental para análises de vibrações induzidas por pessoas caminhando sobre lajes de edifícios (Theoretical-experimental model to analyse vibrations induced by people walking on floor slabs of buildings), $\mathrm{PhD}$ Thesis (in Portuguese), Federal University of Rio de Janeiro, Civil Engineering Department, COPPE/UFRJ, Rio de Janeiro, Brazil, pp. 1-309, 2004

[11]. Winkler, E. "Die Lehre von Elastizitat und Festigkeit" (On Elasticity andFixity), Dominicus, Prague, 1867.

[12]. Terzaghi, K. Evaluation of Coefficients of Subgrade Reaction. Géotechnique, London, v. 4, no 4, December, 1955, p. 297-326.

[13]. Poulos, H.G.; Davis, E.H. Pile Foundation Analysis and Design. John Wiley \& Sons Inc., New York, 1980.

[14]. International Standard Organization / ISO 2631-2. 1989. Evaluation of human exposure to whole-body vibration, Part 2: Human Exposure to Continuous and ShockInduced Vibrations in Buildings (1 to $80 \mathrm{~Hz}$ ), International Standard. 